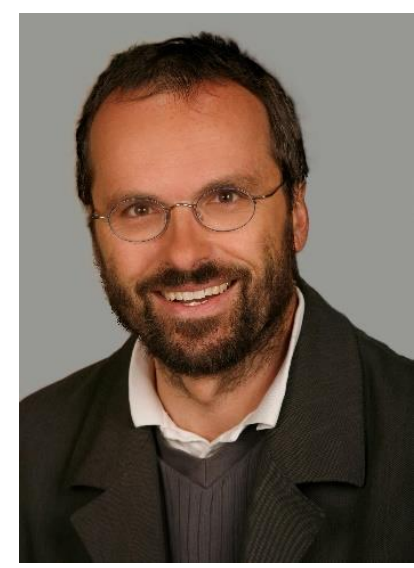

\title{
Energy Efficiency and Renewable Energy: the key factors for a sustainable future
}

\author{
Wolfgang Streicher, \\ Dipl.-Ing. Dr. techn. (University professor) \\ Unit Energy Efficient Buildings, \\ Institute of Structural Engineering and Material Sciences; \\ University of Innsbruck, Austria \\ Email: wolfgang.streicher@uibk.ac.at
}

Climate change is the current biggest challenge for humans. Without mitigation and adaptation in climate change there will be billion of people migrating from one continent to others and within continents. This will probably cause military conflicts and large human suffering. The migration will take place from places where it becomes too hot and/or too dry to do agriculture and to feed the population and no other sources for trading are available into regions with more productive climate. In the last UN Climate Change Conferences, therefore several resolutions to keep the climate change within 1.5 to $2^{\circ} \mathrm{C}$ until 2050 have been taken. The resolution of COP21 in Paris to keep the temperature increase well below $2^{\circ} \mathrm{C}$ is signed already by 172 of 197 parties (http://unfccc.int/paris agreement/items/9485.php).

One very important step to reach these goals is to develop new ideas and implement existing technologies for energy efficiency and renewable energies in a broad range. This will also bring down the costs for the energy system transformation. The limitation of renewable energies in regions with high population density will lead, on the on the one hand, to large energy distribution networks causing new economic and political dependencies between countries, and, on the other hand, to more efficient technologies and systems like energy efficient buildings (for hot and cold climates), energy efficient transportation systems like more public transportation, smaller and electric (or hydrogen) driven cars, and more efficient industrial processes.

Knowledge generation and distribution as done in the International Journal on Renewable Energy and Sustainable Development plays an important role for this further development.

\section{About Professor Wolfgang Streicher}

Wolfgang Streicher is university professor of Energy Efficient Buildings and Renewable Energies at Innsbruck University in Austria and currently ISES Europe president. He teaches Building Services Engineering, HVAC, Heat Pumps, Tube Hydraulics, Modelling, Thermodynamics, Energy and Ecology.

His current research focus is on (i) development of cost and energy efficient systems solutions for HVAC systems including renewables; (ii) energy demand of cities using GIS and bottom up approaches; (iii) hydraulics of complex tube networks; (iv) energy efficient systems for cities (v) solar thermal systems.

He works in these fields since more than 30 years and has published numerous papers in reviewed international journals and conferences. Moreover, he has coordinated and coordinates projects for Austrian institutions as well as the European Commission and the International Energy Agency. 